\title{
LAS “CONDICIONES" A QUE ALUDEN LOS ARTÍCULOS 166 Y 250 N² DEL CÓDIGO CIVIL CHILENO, ¿SON APLICABLES A LA LEGÍTIMA RIGOROSA?
}

\author{
THE CONDITIONS OF ARTICLES 166 AND $250 N^{\circ} 2$ OF THE \\ CHILEAN CIVIL CODE. ARE THEY APPLIABLE TO THE \\ LEGAL PORTION?
}

MARIO OPAZO GONZÁLEZ*

\section{Resumen}

El propósito del presente trabajo es demostrar que, no obstante el tenor literal del artículo 1.192 del Código Civil, es posible sujetar la legítima rigorosa a las "condiciones" contempladas en los artículos 166 y $250 \mathrm{~N}^{\circ}$ 2 del mismo cuerpo legal, toda vez que, en rigor, estas disposiciones no contemplan condiciones.

\section{Palabras Clave}

Legítima rigorosa - condición - patrimonios especiales.

\begin{abstract}
The present work aims to prove that, in spite of the literal meaning of the article 1.192 of the Chilean Civil Code, it is possible to sustain that the "conditions" established by the articles 166 and $250 \mathrm{~N}^{\circ} 2$ of the same Code

Artículo recibido para su evaluación el 23 de marzo de 2021, y aprobado para su publicación el 22 de junio de 2021.

* Magíster en Derecho, mención Derecho Privado, Profesor de Derecho Civil Escuela de Derecho, Facultad de Derecho, Universidad Santo Tomás, sede Viña del Mar, Chile. Email: marioopazo@santotomas.cl
\end{abstract}


are applicable to the legal portion, because, strictly speaking, those articles do not establish conditions.

\section{Keywords}

Legal portion ${ }^{1}-$ condition - special patrimonies.

\section{INTRODUCCIÓN.}

Como es sabido, nuestro sistema sucesorio se rige por el principio de la libertad restringida para testar ${ }^{2}-3-4$; esto quiere decir que el testador debe respetar ciertas asignaciones, llamadas asignaciones forzosas y, si no las respeta, el testamento, en cuanto acto jurídico, si bien es válido, es inoponible a sus asignatarios forzosos en la parte que sobrepasa las asignaciones protegidas ${ }^{5}$, de manera que deberá procederse a modificar el testamento en lo que sea necesario para respetar dichas asignaciones, rigiendo plenamente, en lo demás, la voluntad del testador que se ha volcado

1 Cabe tener presente que se ha utilizado esta expresión como aproximada, pues, como explica Anderson, el Derecho inglés no conoce en estos términos la figura de la legítima, sin perjuicio de las llamadas family provisions. ANDERSON, Miriam: "Una Aproximación al Derecho de Sucesiones Inglés". En Anuario de Derecho Civil, Instituto Nacional de Estudios Jurídicos, Madrid, Fascículo 3, 2006. p. 1.245.

2 ELORRIAGA, Fabián: Derecho Sucesorio. Thomson Reuters, Santiago, $3^{\mathrm{a}}$ ed., 2015. p. 435. En el mismo sentido, MEZA, Ramón: Manual de la Sucesión por Causa de Muerte y Donaciones entre Vivos. Editorial Jurídica de Chile, Santiago, 9a ed., 2008. p. 99.

3 Se ha señalado que la expresión "libertad de testar" tendría dos sentidos: uno negativo o estricto, referido a la posibilidad de poder disponer del propio patrimonio sin que otros se interpongan en esa actividad, y otro positivo, también llamado libertad para testar, que consiste en tomar las propias decisiones con plena validez jurídica, aunque éstas resulten ser inusuales, caprichosas o extrañas. TORRES, Teodora; GARCÍA, M ${ }^{a}$ Paz: La Libertad de Testar: El Principio de Igualdad, la Dignidad de la Persona y el Libre Desarrollo de la Personalidad en el Derecho de Sucesiones. Fundación Coloquio Jurídico Europeo, Madrid, 2014. pp. 16 - 17.

4 Se ha precisado que - en rigor - se trata de una variante de la libertad restringida para testar, cual es "el sistema de distribución forzosa compartido con otro de libre distribución dentro de la cuota de legítima, denominado sistema de mejora. En este modelo se distingue una parte de legítimas y una parte de libre disposición. Dentro de la legítima se distingue una porción que debe ser necesariamente asignada a los parientes y en la cuantía que la ley señala, y otra porción con la que el causante puede mejorar la situación de alguno de ellos". ELORRIAGA, Fabián, op. cit., p. 435.

5 RODRÍGUEZ, Pablo: Instituciones de Derecho Sucesorio. Editorial Jurídica de Chile, Santiago, Vol. 2, $3^{\text {a }}$ ed., 2006 , p. 82. 
en el testamento ${ }^{6}$. Con todo, esta libertad limitada de disposición por parte del testador dependerá de la presencia o ausencia de los asignatarios forzosos ${ }^{7}$, pues, a falta de éstos, la libertad para testar es absoluta.

También es sabido que las asignaciones forzosas, de conformidad con lo dispuesto en el artículo 1.167 de nuestro Código Civil, son los alimentos que se deben por ley a ciertas personas, las legítimas y la cuarta de mejoras en la sucesión de los descendientes, de los ascendientes y del cónyuge sobreviviente; en relación con esta última, debemos agregar al conviviente civil sobreviviente, en virtud de lo dispuesto en el artículo 16 de la Ley $\mathrm{N}^{\mathrm{o}} 20.830$.

De la misma manera, y como una forma de garantizar el respeto a estas asignaciones forzosas, sabido es que el legislador ha dispuesto de una serie de mecanismos de protección, entre los cuales es posible mencionar el hecho que los alimentos que se deben por ley son una baja general de la herencia ${ }^{8}$; la acción de reforma de testamento 9 ; la formación de los acervos imaginarios ${ }^{10}$; la preterición ${ }^{11}$; el desheredamiento ${ }^{12}$; la insinuación de las donaciones ${ }^{13}$; etc.

De las tres asignaciones forzosas que consagra el ordenamiento jurídico chileno, el presente trabajo versará solamente respecto de las legítimas, de manera que no se examinará con detención lo que ocurre con los alimentos que se deben por ley a ciertas personas ni con la cuarta de mejoras.

De la misma manera, de todos los mecanismos de protección de las legítimas solo se examinará uno: el contenido en el artículo 1.192 del Código Civil chileno, y exclusivamente en cuanto establece que la legítima rigorosa no es susceptible de condición alguna. En consecuencia, también conviene dejar establecido que el presente trabajo se referirá solamente a la legítima rigorosa y no a la legítima efectiva, y que versará únicamente en torno a la efectividad de que dicha legítima

6 MEZA, Ramón, op. cit., p. 99.

7 DOMÍNGUEZ B., Ramón; DOMÍNGUEZ A., Ramón: Derecho Sucesorio. Editorial Jurídica de Chile, Santiago, T. II, $3^{\mathrm{a}}$ ed., 2011. p. 895.

8 RUZ, Gonzalo: Explicaciones de Derecho Civil. Sucesiones y Liberalidades. T. VI. Thomson Reuters, Santiago, 2014. p. 524.

9 BARRÍA, Manuel: Asignaciones Forzosas y Libertad de Testar. Thomson Reuters, Santiago, 2015. p. 144.

10 MEZA, Ramón, op. cit., pp. $105-106$.

11 BARRÍA, Manuel, op. cit., p. 147.

12 Ibíd., p. 150.

13 MEZA, Ramón, op. cit., p. 100. 
rigorosa no es susceptible de condición alguna, sin hacer referencia a las demás prohibiciones que contempla la citada disposición, esto es, que no es susceptible de plazo, modo o gravamen alguno. De esta manera, se concluirá que - no obstante el tenor literal del artículo 1.192 del Código Civil - la legítima rigorosa sí admite, excepcionalmente, las "condiciones" que el propio ordenamiento jurídico establece en los artículos 166 y $250 \mathrm{~N}^{\circ} 2$ del mismo cuerpo legal, toda vez que, en rigor, estas últimas disposiciones no contemplan condiciones.

Para llegar a la conclusión ya señalada, se utilizará el método dogmático, analizando los textos de las disposiciones legales del Código Civil chileno; de su modelo, el Código Civil francés, y de las obras doctrinarias y jurisprudenciales nacionales y extranjeras.

\section{PLANTEAMIENTO DEL PROBLEMA.}

Conforme ya se ha expresado, el problema parte del tenor literal del artículo 1.192 de nuestro Código Civil, el cual, en su inciso $1^{\circ}$, establece que "La legítima rigorosa no es susceptible de condición, plazo, modo o gravamen alguno”.

En relación con esta disposición, se ha sostenido que su fundamento se encuentra en que, desde un punto de vista cuantitativo, la legítima rigorosa es considerada como un derecho; en consecuencia, si se permitiera el establecimiento de modalidades a la referida legítima, sería habitual incorporarlas a los testamentos con el objeto de eludir el mencionado derecho de los legitimarios, favoreciendo a uno de ellos por sobre los otros, o bien, favoreciendo a un tercero extraño a la sucesión ${ }^{14}$ en perjuicio de los legitimarios; en otras palabras, de admitirse estas modalidades o gravámenes, el testador podría violar la legítima rigorosa de una manera indirecta ${ }^{15}$. En consecuencia, esta prohibición de imponer modalidades a la legítima rigorosa sería absoluta, toda vez que comprende tanto a las modalidades que perjudiquen o que favorezcan a los legitimarios ${ }^{16}$, de manera que, por la sola disposición de la ley, se trata de una asignación que siempre será pura y simple ${ }^{17}$, ya que corresponde a un derecho que el

14 BARRÍA, Manuel, p. 129.

15 TRONCOSO, Hernán: Derecho Sucesorio. Legal Publishing, Santiago, 6a ed., 2009. p. 148.

16 DOMÍNGUEZ B., Ramón; DOMÍNGUEZ A., Ramón, op. cit., p. 940.

17 RODRÍGUEZ, Pablo, op. cit., Vol. 1, p. 324. 
legitimario adquiere directamente de la ley, por lo que el testador no puede restringirla ni impedir que produzca sus efectos normales ${ }^{18}$.

Con todo, un sector de la doctrina ha identificado una excepción a esta regla que prohíbe que la legítima rigorosa se sujete a una condición: el caso del artículo 86 de la Ley General de Bancos ${ }^{19}$. Dicha disposición se coloca en la hipótesis en que se hayan dejado bienes que constituyan su legítima rigorosa a una persona incapaz, bajo condición de que tales bienes sean administrados por un banco mientras dure la incapacidad del legitimario. Se entiende que esta condición es válida, correspondiendo a una comisión de confianza y teniendo el banco las facultades de un curador adjunto respecto de dichos bienes.

No obstante lo señalado, la doctrina nacional no es unánime a la hora de considerar si se trata de una excepción real o aparente. Por una parte, autores como Somarriva ${ }^{20}$, Rodríguez ${ }^{21}$, Meza $^{22}$ y Ramos ${ }^{23}$ plantean que estamos frente a una verdadera excepción, esto es, que la única hipótesis en que el legislador admitiría que la legítima rigorosa se sujete a una condición sería este caso de la Ley General de Bancos. Por otra parte, autores como Elorriaga y los Domínguez sostienen que se trata de una excepción aparente, ya que ella solo se aplica cuando el legitimario es una persona incapaz y el efecto de la "condición" no es que la adquisición, el ejercicio ni la extinción de la legítima sean alterados por la disposición testamentaria condicional ${ }^{24}$, sino que es que los bienes que adquiere el legitimario incapaz no sean administrados por su representante legal, sino por el banco, de manera que solo se está reemplazando a un administrador por otro ${ }^{25}$, pero no se está privando al legitimario de su legítima, lo que constituye el fundamento del artículo 1.192 del Código Civil.

Sin perjuicio de lo expuesto, encontramos, además, dos disposiciones que admiten una liberalidad mortis causa sujeta a una condición,

18 RUZ, Gonzalo, op. cit., p. 519.

19 Cabe tener presente que también se ha identificado como excepción al artículo 1.192 del Código Civil, el caso del artículo 1.337 regla $10^{\mathrm{a}}$, que no será analizado, pues sería una excepción a la prohibición de imponer gravámenes a la legítima rigorosa.

20 SOMARRIVA, Manuel: Derecho Sucesorio. Editorial Jurídica de Chile, Santiago, T. II, $8^{\mathrm{a}}$ ed., 2005. p. 382.

21 RODRÍGUEZ, Pablo, op. cit., Vol. 1, p. 324.

22 MEZA, Ramón, op. cit., p. 100.

23 RAMOS, René: Sucesión por Causa de Muerte. Editorial Jurídica de Chile, Santiago, 2010. p. 123.

24 DOMÍNGUEZ B, Ramón y DOMÍNGUEZ A., Ramón, op. cit., p. 940.

25 ELORRIAGA, Fabián, op. cit., pp. $464-466$. 
estableciéndose la validez de la misma: los artículos 166 y $250 \mathrm{~N}^{\circ} 2$, ambos de nuestro Código Civil.

La primera de estas disposiciones se coloca en el caso de que a la mujer casada bajo régimen de sociedad conyugal se haga una donación o se deje una herencia o legado bajo condición de que los bienes donados, heredados o legados no sean administrados por el marido. Esta condición es válida y, para evitar que la administración de tales bienes corresponda al marido, la ley establece que dichos bienes darán origen a un patrimonio distinto de la mujer, el cual será administrado por ésta.

La segunda de estas disposiciones establece algo similar: se coloca en el caso de que al hijo sujeto a patria potestad se haga una donación o se deje una herencia o legado bajo condición de que la administración o el goce de tales bienes no corresponda al padre o madre que tiene la patria potestad, o de que el hijo obtenga su emancipación, o de que tal goce corresponda al hijo. Al igual que en el caso anterior, la ley considera que tal condición es válida y se entiende cumplida dando origen a un patrimonio distinto para el hijo sujeto a patria potestad, llamado peculio adventicio extraordinario ${ }^{26}$, en el que el goce de tales bienes no corresponderá al padre o madre que tenga la patria potestad.

Como puede observarse, estas dos disposiciones pueden aplicarse perfectamente a casos en que el donatario, heredero o legatario sea un legitimario. Por ejemplo, pensemos que fallece una persona y deja una herencia constitutiva de su legítima rigorosa o un legado con cargo a la misma, a su hija que está casada bajo régimen de sociedad conyugal, y el padre o madre que fallece deja tal herencia o legado bajo la condición de que los bienes heredados o legados no sean administrados por el marido, o bien, fallece el padre de un hijo sujeto a patria potestad y, por testamento, dispone que la administración o goce de los bienes heredados constitutivos de su legítima rigorosa, o legados con cargo a la misma, no corresponda a la madre que tiene el ejercicio de la patria potestad.

El problema que surge, como puede advertirse, será si ¿valen tales condiciones cuando la liberalidad que se deja a la mujer casada bajo régimen de sociedad conyugal o al hijo sujeto a patria potestad corresponden a su legítima rigorosa? o, por el contrario, aplicando el artículo 1.192 inciso $1^{\circ}$ del Código Civil ¿debiéramos sostener que dichas condiciones no son

$\overline{26}$ ACUÑA, Marcela: "Relaciones Jurídicas entre los Padres y el (la) Hijo (a). Filiación". En: Del Picó, Jorge: Derecho de Familia. Thomson Reuters, Santiago, 2a ed., 2016. p. 525. 
válidas? En otras palabras, frente al conflicto que puede surgir entre los artículos 166 y $250 \mathrm{~N}^{\circ} 2$ del Código Civil, por una parte, y el artículo 1.192 del mismo cuerpo legal, por otra, la pregunta que surge es ¿cuál de estas disposiciones se aplica? Si decimos que los dos primeros artículos, debiéramos llegar a la conclusión de que el artículo 1.192 del Código Civil encontraría dos excepciones en las referidas disposiciones; por el contrario, si decimos que el que resulta aplicable es el artículo 1.192 del Código Civil, debiéramos llegar a la conclusión de que los artículos 166 y $250 \mathrm{~N}^{\mathrm{o}} 2$ del mismo código no tendrían cabida cuando la liberalidad recae sobre la legítima rigorosa.

Frente a este problema, Pablo Rodríguez, al explicar el caso del artículo 166 del Código Civil, da a entender que esta disposición tiene como límite la situación del artículo 1.192 del mismo cuerpo legal, esto es, que la legítima rigorosa, en cuanto asignación forzosa, no puede ser objeto de condición, plazo, modo o gravamen alguno, de manera que la condición contemplada en el artículo 166 del referido código no vale cuando se aplica a la legítima rigorosa ${ }^{27}$.

Por otro lado, los Domínguez, refiriéndose al caso del artículo $250 \mathrm{~N}^{\circ} 2$ del Código Civil, niegan que la condición a que se refiere este artículo pueda extenderse a la legítima rigorosa del hijo sujeto a patria potestad, de manera que, respecto de ella, el padre o madre que tenga la patria potestad siempre tendrá el derecho legal de goce y la administración de dicha legítima, por aplicación de lo dispuesto en el artículo 1.192 inciso $1^{\circ}$ del Código Civil28.

Conforme se ha expuesto, la tesis que se probará en el presente trabajo es que la legítima rigorosa puede sujetarse a las "condiciones" contempladas en los artículos 166 y $250 \mathrm{~N}^{\circ} 2$ del Código Civil, toda vez que, en rigor, tales disposiciones no se refieren a condiciones.

\section{III. ¿SON REALMENTE CONDICIONES LAS FIGURAS CONTEMPLADAS EN LOS ARTÍCULOS 166 Y 250 N N $^{\circ} 2$ DEL CÓDIGO CIVIL?}

\section{Caso del artículo 166 del Código Civil.}

Como se anticipó, este caso se presenta cuando a la mujer casada bajo régimen de sociedad conyugal se hace una donación, o se le deja

27 RODRÍGUEZ, Pablo: Regímenes Patrimoniales. Editorial Jurídica de Chile, Santiago, 1996. pp. $214-215$.

28 DOMÍNGUEZ B., Ramón y DOMÍNGUEZ A., Ramón, op. cit., p. 940. 
una herencia o legado con la condición precisa de que las cosas donadas, heredadas o legadas no sean administradas por su marido, y la mujer acepta la donación, herencia o legado. Se entiende que esta condición es válida $\mathrm{y}$, respecto de los bienes que han sido objeto de la liberalidad, la mujer se considera separada de bienes ${ }^{29}$, de manera que a ella le corresponde la administración de los mismos.

De no existir esta disposición, y si se tratara de bienes inmuebles, estos ingresarían al haber propio de la mujer y serían administrados por su marido; mientras que, si se tratara muebles, ingresarían al haber relativo de la sociedad conyugal y también serían administrados por el marido.

\section{Caso del artículo $250 \mathbf{N}^{\circ} 2$ del Código Civil.}

Conforme se señaló previamente, este caso se presenta cuando al hijo sujeto a patria potestad se hace una donación, o se deja una herencia o legado con la condición precisa de que, respecto de las cosas donadas, heredadas o legadas, no tenga el goce o la administración el padre o madre que ejerce la patria potestad, o bien, de que el hijo obtenga la emancipación, o de que el goce de tales bienes corresponda al hijo.

En esta situación, la ley interpreta la voluntad del donante o causante excluyendo estos bienes del derecho legal de goce, disponiendo que los mismos integren un patrimonio distinto del hijo, llamado peculio adventicio extraordinario, y que el titular de la patria potestad no tenga el derecho legal de goce sobre ellos.

Tratándose de la condición de obtener la emancipación, se ha sostenido que, como la emancipación del hijo es un hecho que no puede depender de la voluntad del donante o testador, ya que opera por resolución judicial o causa legal, la ley interpreta la voluntad del testador o donante, dando por cumplida la condición en una forma que se acerca al deseo de quien hace la liberalidad, privando al titular de la patria potestad del derecho de goce sobre los bienes del hijo que éste adquirió por donación, herencia o legado, bajo la señalada condición ${ }^{30}$.

En este caso, de conformidad con lo dispuesto en el artículo 253 inciso $2^{\circ}$ del Código Civil, el goce de tales bienes corresponderá al

29 RAMOS, René: Derecho de Familia. Editorial Jurídica de Chile, Santiago, $7^{\text {a }}$ ed., 2007, T. I. p. 46.

30 TRONCOSO, Hernán: Derecho de Familia. Thomson Reuters, Santiago, $16^{\text {a }}$ ed., 2017. p. 321 . 
otro padre o madre, pero si este también estuviese impedido, la plena propiedad corresponderá al hijo, debiendo nombrársele un curador para la administración de los mismos ${ }^{31}$.

A juicio de Abeliuk, el caso de las cosas donadas, heredadas o legadas, cuando el donante o testador ha estipulado que no tenga el goce o la administración el padre o madre que ejerce la patria potestad, puede aplicarse a las legítimas, toda vez que, no solo el legislador no ha utilizado la palabra "condición" en el artículo $250 \mathrm{~N}^{\mathrm{o}} 2$ del Código Civil, sino que, en rigor, no se trata ni de una condición ni de un gravamen, sino de un beneficio para el hijo ${ }^{32}$.

\section{Los casos a que se refieren los artículos 166 y $250 \mathrm{~N}^{\circ} 2$ del Código Civil, en rigor, no contemplan condiciones.}

Como hemos advertido, los artículos 166 y $250 \mathrm{~N}^{\circ} 2$ del Código Civil se refieren a ciertas liberalidades que se hacen a una persona - mujer casada bajo régimen de sociedad conyugal en el primer caso, e hijo sujeto a patria potestad en el segundo - bajo ciertas "condiciones", y tales disposiciones entrarían en conflicto con el artículo 1.192 del mismo cuerpo legal, en tanto las referidas liberalidades correspondan a la legítima rigorosa, ya que esta disposición prohíbe que la señalada legítima se sujete a condición alguna. En consecuencia, estaríamos en presencia de una antinomia y el problema consistiría en determinar cuál de estas disposiciones se aplica: si se estima que deben aplicarse los artículos 166 y $250 \mathrm{~N}^{\circ} 2$ del Código Civil, debiéramos concluir que, no obstante el tenor literal del artículo 1.192 del mismo cuerpo legal, éste tendría dos excepciones en las disposiciones ya citadas; en cambio, si se estima que prevalece el artículo 1.192 del Código Civil, debiésemos sostener que los artículos 166 y $250 \mathrm{~N}^{\circ} 2$ del mismo código tendrían como limitación que tales liberalidades no correspondan a la asignación de la legítima rigorosa.

Conforme se ha adelantado, estimamos que - frente a esta aparente contradicción - cabe aplicar los artículos 166 y $250 \mathrm{~N}^{\mathrm{o}} 2$ del Código Civil frente al artículo 1.192 del mismo cuerpo legal, debido a que, si bien aquellas disposiciones se refieren o han sido entendidas como que se

31 QUINTANA, Ma Soledad: Derecho de Familia. Ediciones Universitarias de Valparaíso, Valparaíso, 2 ${ }^{\mathrm{a}}$ ed., 2015. p. 394.

32 ABELIUK, René: La Filiación y sus Efectos. Editorial Jurídica de Chile, Santiago, T. I, 2000. p. 452. 
refieren a una liberalidad sujeta a "condición", en rigor, no estamos frente a esta modalidad.

En efecto, a partir de los artículos 1.473 y 1.070 del Código Civil chileno, doctrinariamente se ha definido a la condición como "el hecho futuro e incierto del cual depende el nacimiento o la extinción de un derecho y su obligación correlativa" ${ }^{33}$, reconociéndose como sus elementos constitutivos la futureidad y la incertidumbre ${ }^{34}$. De esta manera, se ha entendido que obligación condicional "es aquella cuya existencia o cuya resolución depende de un acontecimiento futuro e incierto" ${ }^{35}$, por lo que su nacimiento o extinción es incierta mientras no se tenga conocimiento respecto a si ocurrirá o no aquel hecho del cual depende, esto es, no se sepa si, en definitiva, existirá o no ${ }^{36}$. Como explica Daniel Peñailillo, es la eficacia de un acto la que se somete a un hecho futuro e incierto ${ }^{37}$.

Como consecuencia de lo señalado, una de las principales clasificaciones que se formula de las condiciones es aquella que distingue entre condición suspensiva y condición resolutoria, estableciéndose como criterio de clasificación los efectos que produce la condición. La primera ha sido entendida como el hecho futuro e incierto del cual depende la existencia o el nacimiento de un derecho y de su obligación correlativa; mientras que la segunda ha sido definida como el hecho futuro e incierto del cual depende la extinción o resolución de un derecho y de su obligación correlativa ${ }^{38}$. Con todo, se ha sostenido que esta clasificación es superficial, pues, por una parte, toda condición tiene un carácter suspensivo, ya que incluso la condición resolutoria suspende la extinción de un derecho y, por otra, porque toda condición será suspensiva o resolutoria dependiendo del punto de vista que se adopte, esto es, dependiendo del sujeto que mire esta relación obligatoria condicional ${ }^{39}$.

Estas consideraciones respecto de la condición pueden verse también en el modelo que siguió don Andrés Bello, esto es, en el Código Civil

33 TRONCOSO, Hernán: De las Obligaciones. Thomson Reuters, Santiago, $7^{\mathrm{a}}$ ed., 2011. p. 113 .

34 Ibíd., pp. $113-115$.

35 ALESSANDRI, Arturo: Teoría de las Obligaciones. Editorial Jurídica Ediar Conosur Ltda., Santiago, 1988. p. 164.

36 Ídem.

37 PEÑAILILLO, Daniel: Obligaciones. Teoría General y Clasificaciones. La Resolución por Incumplimiento. Editorial Jurídica de Chile, Santiago, 2003. p. 354.

38 RAMOS, René: De las Obligaciones. Legal Publishing, Santiago, $3^{\mathrm{a}}$ ed., 2008. p. 130.

39 ABELIUK, René: Las Obligaciones. Thomson Reuters, Santiago, $6^{\mathrm{a}}$ ed., 2014. p. 613. 
francés. En dicho país se ha señalado que la condición es un evento futuro, pero incierto, del cual depende, sea la existencia de una obligación, esto es, su nacimiento, en cuyo caso se habla de condición suspensiva; sea su resolución, en cuyo caso estamos frente a la condición resolutoria ${ }^{40}$. De esta manera, se habla de condición suspensiva, porque la efectividad de la obligación está subordinada a la realización de un evento futuro e incierto, cuyo cumplimiento hace que la obligación pase a ser pura y simple; mientras que, por otro lado, se habla de condición resolutoria cuando el cumplimiento de un evento futuro e incierto importa la aniquilación de una obligación existente y ya eficaz ${ }^{41}$.

De los dos elementos constitutivos de la condición, la futureidad y la incertidumbre, el que resulta ser característico de ella es este último. La incertidumbre se refiere a que el hecho constitutivo de la condición puede o no acontecer ${ }^{42}$. Además, tal incertidumbre debe ser objetiva, esto es, que el desconocimiento respecto a si el hecho acaecerá o no debe depender del acontecimiento constitutivo de la condición considerado en sí mismo y no en la previsión o conocimiento que tengan las partes o alguna de ellas ${ }^{43}$. Como señalan Buffelan - Lanore y Larribau - Terneyre, para estar frente a una verdadera condición es necesario que el evento sea incierto, no solo en cuanto a su fecha, sino que - en rigor - en cuanto a su realización, pues éste es el elemento que permite distinguir una condición de un plazo $^{44}$.

De acuerdo con lo señalado precedentemente, una de las características de las condiciones es que en el futuro ha de producirse un hecho que, al momento de la celebración del acto jurídico, no se sabe si ocurrirá o no. De esta manera, la ocurrencia del evento constitutivo de la condición, de conformidad con lo dispuesto en el artículo 1.477 del Código Civil chileno, puede depender de la voluntad de una de las partes, de un tercero o de un acaso, o de una combinación de las alternativas precedentes; en el

40 BUFFELAN - LANORE, Yvaine; LARRIBAU - TERNEYRE, Virginie: Droit Civil. Les Obligations. Dalloz, Paris, 16 édition, 2018. p. 98.

41 TERRÉ, François; SIMLER, Philippe; LEQUETTE, Yves; CHÉNEDÉ, François: Droit Civil. Les Obligations. Dalloz, Paris, 12ª édition, 2018. p. 1.405.

42 LLUELLES, Didier; MOORE, Benoît: Droit des Obligations. Les Éditions Thémis, Montréal, $2^{\mathrm{a}}$ édition, 2012. p. 1.459.

43 DOMÍNGUEZ, Ramón: Teoría General del Negocio Jurídico. Editorial Prolibros, Santiago, $3^{\text {a }}$ ed., 2020. p. 295.

44 BUFFELAN - LANORE, Yvaine; LARRIBAU - TERNEYRE, Virginie, op. cit., p. 102. 
primer caso, hablamos de una condición potestativa; en el segundo, de una condición casual y, en el tercero, de una condición mixta ${ }^{45}$.

Esta clasificación también había sido considerada en el modelo francés que siguió don Andrés Bello, en los antiguos artículos 1.169, 1.170 y 1.171 del Code.

El primero de ellos señalaba que la condición casual era aquélla que depende del azar y que de ninguna manera depende del poder del acreedor ni del deudor. De esta manera, la obligación está subordinada a un evento natural o a la voluntad o comportamiento de un tercero. Después de la reforma del año 2016, los nuevos textos legales no definen la condición casual, que es el arquetipo de la condición ${ }^{46}$.

La segunda de las referidas disposiciones definía la condición potestativa como aquélla que hace depender la ejecución de la convención a un evento que está en poder de una o de la otra de las partes contratantes que se produzca o de impedirlo, distinguiendo entre condición puramente potestativa, que depende exclusivamente de la voluntad de una de las partes, y condición simplemente potestativa, que depende, a la vez, de la voluntad de una de las partes y de una circunstancia de la cual no tiene el control.

Finalmente, la última de las disposiciones mencionadas definía a la condición mixta como aquélla que depende, a la vez, de la voluntad de una de las partes contratantes y de la voluntad de un tercero; sin perjuicio de ello, Terré, Simler, Lequette y Chénedé sostienen que la jurisprudencia francesa no siguió esa lectura restrictiva de la disposición legal en comento, entendiendo que toda especie de elemento extrínseco es susceptible de justificar la calificación de condición mixta ${ }^{47}$.

Cabe tener presente que las definiciones contenidas en los artículos mencionados fueron derogadas con la reforma del año 2016, estableciéndose solamente, en la actualidad, en el artículo $1.304-2$ del Code, que es nula la condición cuya realización depende de la sola voluntad del deudor.

A partir de lo expuesto, cabe preguntarse si la condición de que el marido no administre las cosas donadas, heredadas o legadas, o de que no tenga el goce o la administración de las cosas donadas, heredadas o legadas

45 RUZ, Gonzalo: Explicaciones de Derecho Civil. Obligaciones. Thomson Reuters, Santiago, 2011. pp. $180-185$.

46 TERRÉ, François; SIMLER, Philippe; LEQUETTE, Yves; CHÉNEDÉ, François, op. cit., p. 1.409.

47 Ibíd., p. 1.410. 
el padre o madre que ejerce la patria potestad, o de que el hijo tenga el goce de tales cosas, o de que el hijo obtenga la emancipación responden a la definición de condición dada y, en particular, si cumplen con los requisitos de la futureidad e incertidumbre, de manera que, mientras no se cumpla con tal evento, no se adquiere o no se extingue el derecho a tales bienes y si, para cuyo cumplimiento se requiere de la voluntad de una de las partes, de la voluntad de un tercero o de un acaso, o de una combinación de las situaciones anteriores.

La pregunta surge porque existen, a lo menos, tres razones que obstan a que sea posible sostener que los artículos 166 y $250 \mathrm{~N}^{\circ} 2$ del Código Civil chileno contemplan, realmente, condiciones.

La primera de ellas es que, de ser efectivamente condiciones, su cumplimiento debiera depender de la voluntad de alguna de las partes, de la voluntad de un tercero, de un acaso o de una combinación entre la voluntad de una de las partes y la voluntad de un tercero, o de una combinación entre la voluntad de una de las partes y un acaso; sin embargo, el cumplimiento de las referidas "condiciones" depende de la ley, pues es el ordenamiento jurídico el que establece que dichas "condiciones" se cumplen generándose un patrimonio distinto: un patrimonio satélite en el caso de la mujer casada bajo régimen de sociedad conyugal, o el peculio adventicio extraordinario en el caso del hijo sujeto a patria potestad, sin que en la generación de tales patrimonios intervenga la voluntad de una de las partes, la voluntad de un tercero o un acaso $^{48}$.

La segunda es que, si realmente fuesen condiciones, debiera tratarse de hechos inciertos. Como explican Lluelles y Moore, la noción de incertidumbre no siempre es fácil de entender, pues, tratándose de hechos de la naturaleza, en general no se presentan problemas para determinar si son o no inciertos; mientras que, tratándose de los hechos del ser humano, sí se ha presentado la dificultad de precisar si son o no inciertos, pues muchos de ellos se pueden verificar si el derecho puede forzar su realización ${ }^{49}$.

48 Podría pensarse que interviene la voluntad de una de las partes: de la mujer o del hijo (o del representante de éste) cuando acepta la liberalidad; sin embargo, en rigor, ése no es el hecho constitutivo de la "condición", sino que es que el marido no tenga la administración, o que el goce o la administración no corresponda al padre o madre que ejerce la patria potestad, o que el hijo adquiera la emancipación, o que el goce corresponda al hijo.

49 LLUELLES, Didier; MOORE, Benoît, op. cit., pp. $1.459-1.460$. 
Sin embargo, este elemento de la condición no está presente en los casos que se analizan, toda vez que, si llegan a establecerse esas "condiciones" de que el marido no administre las cosas donadas, heredadas o legadas, o de que el goce o la administración no corresponda al padre o madre que tiene la patria potestad, o de que el hijo adquiera la emancipación, o de que el goce corresponda al hijo, se trata de hechos ciertos, pues la "condición" necesariamente se va cumplir por disposición de la ley, generándose un patrimonio distinto: un patrimonio satélite en el caso de la mujer casada bajo régimen de sociedad conyugal, o el peculio adventicio extraordinario en el caso del hijo sujeto a patria potestad. En efecto, en estas situaciones cabe preguntarse si es posible que tales patrimonios no lleguen a generarse y la respuesta es negativa: cumpliéndose los requisitos que establece la ley, tales patrimonios se forman y con ello se cumple la "condición", pero ello siempre va a ocurrir, por lo que no puede sostenerse que se trate de un hecho incierto.

En tercer lugar, de ser condiciones, debiera subordinarse a su cumplimiento el nacimiento o la extinción de un derecho, pues solo así podría ser calificada de una condición suspensiva o resolutoria. Sin embargo, se advierte que ni el nacimiento ni la extinción del derecho sobre las cosas donadas, heredadas o legadas están subordinados al cumplimiento de un hecho futuro e incierto. Tal como se mencionó a propósito del artículo 86 de la Ley General de Bancos, el donatario, heredero o legatario adquiere inmediatamente y sin la posibilidad de que su derecho se vea extinguido, solo que, para poder cumplir con la voluntad del donante o testador, se generará un patrimonio distinto para la mujer o el hijo donatario, heredero o legatario. Y, de manera similar, se trata - en el primer caso - de que la mujer administre tales bienes y, en el segundo, de que el goce o la administración de los bienes no corresponda al padre o madre que ejerce la patria potestad.

Tampoco es posible considerarlas como condiciones juris, toda vez que éstas proceden de la naturaleza del acto o son establecidas por el ordenamiento jurídico, pero no por el autor o las partes del mismo ${ }^{50}$. En efecto, en los casos que tratamos, la condición ha sido impuesta por el testador o el donante y no por el ordenamiento jurídico.

50 DOMÍNGUEZ, Ramón, op. cit., p. 296. 


\section{CONCLUSIONES.}

El problema que se ha planteado ha sido la aparente contradicción entre los artículos 166 y $250 \mathrm{~N}^{\circ} 2$ del Código Civil chileno, por una parte, y el artículo 1.192 del mismo cuerpo legal, por otra. La razón se encuentra en que las primeras de estas disposiciones establecen, respectivamente, que en caso que a la mujer casada bajo régimen de sociedad conyugal se deje una donación, herencia o legado bajo condición de que las cosas donadas, heredadas o legadas no sean administradas por el marido, y la mujer acepta la liberalidad, se genera un patrimonio especial para la cónyuge, el cual es administrado por ella; mientras que la segunda de dichas disposiciones señala que si al hijo sujeto a patria potestad se deja una donación, herencia o legado bajo condición de que la administración o el goce de tales bienes no lo tenga el padre o madre que ejerce la patria potestad, o de que el hijo obtenga la emancipación, o de que el goce corresponda al hijo, con las cosas objeto de la liberalidad se genera un patrimonio separado para ese hijo, llamado peculio adventicio extraordinario, de manera que el goce de los bienes que integran este peculio no corresponda al padre o madre que ejerce la patria potestad. Por su parte, el artículo 1.192 del mismo cuerpo legal señala que la legítima rigorosa no puede sujetarse a condición alguna, de manera que cabe preguntarse si es posible dar origen a los patrimonios de los artículos 166 y $250 \mathrm{~N}^{\circ} 2$ del Código Civil cuando la liberalidad corresponde a la legítima rigorosa.

En principio debiera sostenerse que no es posible, toda vez que el tenor literal del artículo 1.192 del Código Civil es claro al señalar que la legítima rigorosa no es susceptible de condición alguna, lo que se justifica en su carácter de asignación forzosa, toda vez que - de aceptarse su sujeción a alguna condición, suspensiva o resolutoria - se corre el riesgo de que el testador pueda privar de ella al legitimario.

Sin embargo, un examen más acabado de los artículos 166 y 250 $\mathrm{N}^{\mathrm{o}} 2$ del Código Civil nos lleva a la conclusión que las pretendidas "condiciones" a que aluden, en rigor, no son tales. En efecto, para estar frente a una condición es necesario que el evento que la constituye sea un hecho incierto, esto es, que no se sepa si ocurrirá o no; además, es necesario que la ocurrencia de ese evento dependa de la voluntad de alguna de las partes, de la voluntad de un tercero o de un acaso, o de una combinación entre la voluntad de alguna de las partes y la voluntad de un tercero o de un acaso y, finalmente, es necesario que el hecho constitutivo de la condición subordine el nacimiento o la extinción del derecho a que 
se refiere el acto jurídico, para que la condición pueda ser calificada de suspensiva o resolutoria.

De esta manera, al examinar el evento constitutivo de las pretendidas "condiciones" a que aluden los artículos en comento, se advierte que no se trata de hechos inciertos, pues, cumpliéndose los requisitos exigidos por ambas disposiciones, el hecho se va a producir, es decir, no hay dudas respecto de su ocurrencia; por otro lado, el cumplimiento de los mismos depende de la ley, ya que es ésta la que establece que, concurriendo ciertos requisitos, se generará un patrimonio distinto para la mujer casada bajo régimen de sociedad conyugal o para el hijo sujeto a patria potestad y, finalmente, ni el nacimiento ni la extinción del derecho sobre los bienes donados, heredados o legados se encuentran subordinados al acaecimiento de un hecho futuro e incierto, toda vez que solo se trata - en el primer caso - de sustituir al administrador normal de estos bienes por otro y - en el segundo - de que el goce o la administración de tales bienes no corresponda al padre o madre que tiene la patria potestad.

En consecuencia, esa aparente contradicción, en rigor, no es tal, ya que los artículos 166 y $250 \mathrm{~N}^{\circ} 2$ del Código Civil, si bien se refieren o se ha entendido que aluden a ciertas "condiciones", en realidad se trata de estipulaciones señaladas por el testador o donante referidas a la administración o goce de las cosas donadas, heredadas o legadas, pero que no son condiciones en sentido técnico, ya que les falta la incertidumbre, su cumplimiento depende de la ley y no de la voluntad de alguna de las partes, de la voluntad de un tercero, de un acaso, o de una combinación entre las alternativas anteriores, y su ocurrencia no está subordinando ni el nacimiento ni la extinción de un derecho.

\section{BIBLIOGRAFÍA.}

ABELIUK, René: La Filiación y sus Efectos. Editorial Jurídica de Chile, Santiago, T. I, 2000.

ABELIUK, René: Las Obligaciones. Thomson Reuters, Santiago, $6^{\mathrm{a}}$ ed., T. I, 2014.

ACUÑA, Marcela: "Relaciones Jurídicas entre los Padres y el (la) Hijo (a). Filiación". En: Del Picó, Jorge: Derecho de Familia. Thomson Reuters, Santiago, $2^{\mathrm{a}}$ ed., 2016. 
ALESSANDRI, Arturo: Teoría de las Obligaciones. Editorial Jurídica Ediar Conosur Ltda., Santiago, 1988.

ANDERSON, Miriam: "Una Aproximación al Derecho de Sucesiones Inglés". En Anuario de Derecho Civil, Instituto Nacional de Estudios Jurídicos, Madrid, Fascículo 3, 2006.

BARRÍA, Manuel: Asignaciones Forzosas y Libertad de Testar. Thomson Reuters, Santiago, 2015.

BUFFELAN - LANORE, Yvaine; LARRIBAU - TERNEYRE, Virginie: Droit Civil. Les Obligations. Dalloz, Paris, 16ª ed., 2018.

DOMÍNGUEZ B., Ramón; DOMÍNGUEZ A., Ramón: Derecho Sucesorio. Editorial Jurídica de Chile, Santiago, 3ª ed., 2011.

DOMÍNGUEZ, Ramón: Teoría General del Negocio Jurídico. Prolibros, Valparaíso, $3^{\mathrm{a}}$ ed., 2020.

LLUELLES, Didier; MOORE, Benoît: Droit des Obligations. Les Éditions Thémis, Montréal, $2^{\mathrm{a}}$ ed., 2012.

MEZA, Ramón: Manual de la Sucesión por Causa de Muerte y Donaciones entre Vivos. Editorial Jurídica de Chile, Santiago, $9^{a}$ ed., 2008.

PEÑAILILLO, Daniel: Obligaciones. Teoría General y Clasificaciones. La Resolución por Incumplimiento. Editorial Jurídica de Chile, Santiago, 2003.

QUINTANA, Ma Soledad: Derecho de Familia. Ediciones Universitarias de Valparaíso, Valparaíso, $2^{\mathrm{a}}$ ed., 2015.

RAMOS, René: Derecho de Familia. Editorial Jurídica de Chile, Santiago, T. I, $7^{\mathrm{a}}$ ed., 2007.

RAMOS, René: De las Obligaciones. Legal Publishing, Santiago, $3^{a}$ ed., 2008.

RAMOS, René: Sucesión por Causa de Muerte. Editorial Jurídica de Chile, Santiago, 2010.

RODRÍGUEZ, Pablo: Regímenes Patrimoniales. Editorial Jurídica de Chile, Santiago, 1996.

RODRÍGUEZ, Pablo: Instituciones de Derecho Sucesorio. Pérdida, Defensa y Pago de las Asignaciones. Ejecutores Testamentarios. Partición. Editorial Jurídica de Chile, Santiago, Vol. 2, 3ª ed., 2006. 
RUZ, Gonzalo: Explicaciones de Derecho Civil. Obligaciones. T. II. Thomson Reuters, Santiago, 2011.

RUZ, Gonzalo: Explicaciones de Derecho Civil. Sucesiones y Liberalidades. T. VI. Thomson Reuters, Santiago, 2014.

SOMARRIVA, Manuel: Derecho Sucesorio. Editorial Jurídica de Chile, Santiago, T. II, $8^{\mathrm{a}}$ ed., 2005.

TERRÉ, François; SIMLER, Philippe; LEQUETTE, Yves; CHÉNEDÉ, François: Droit Civil. Les Obligations. Dalloz, Paris, 12a ed., 2018.

TORRES, Teodora; GARCÍA, Ma Paz: La Libertad de Testar: El Principio de Igualdad, la Dignidad de la Persona y el Libre Desarrollo de la Personalidad en el Derecho de Sucesiones. Fundación Coloquio Jurídico Europeo, Madrid, 2014.

TRONCOSO, Hernán: Derecho Sucesorio. Legal Publishing, Santiago, $6^{\text {a }}$ ed., 2009.

TRONCOSO, Hernán: De las Obligaciones. Thomson Reuters, Santiago, $7^{\mathrm{a}}$ ed., 2011.

TRONCOSO, Hernán: Derecho de Familia. Thomson Reuters, Santiago, $16^{\mathrm{a}}$ ed., 2017. 